6 Weiner DA, Ryan TJ, McCabe CH, Kennedy JW, Schloss M, Tristani F, et al. Exercise stress testing: correlations among history of angina, ST segment response and prevalence of coronary artery disease in the coronary artery surgery study (CASS). N Engl J Med 1979;301:230-5

7 Sullivan AK, Holdright DR, Wright CA, Sparrow JL, Cunningham D, Fox KM. Chest pain in women: clinical, investigative and prognostic features. BMJ 1994;308:883-6.

8 Lincoff AM, Califf RM, Ellis SG, Sigmon KN, Lee KL, Leimberger JD, for the Thrombolysis and Angioplasty in Myocardial Infarction Study Group. Thrombolytic therapy for women with myocardial infarction: is there a gender gap? J Am Coll Cardiol 1993;22:1780-7.

9 Clarke KW, Gray D, Keating NA, Hampton JR. Do women with acute myocardial infarction receive the same treatment as men? $B M J$ 1994;309:563-6.

10 Wilkinson P, Laji K, Ranjadayalan K, Parsons L, Timmis AD. Acute myocardial infarction in women: survival analysis in first six months. BMJ 1994;309:566-90.

11 Hannaford PC, Kay CR, Ferry S. Agism as explanation for sexism in provision of thrombolysis. BMJ 1994; 309: 573 .

12 Mark DB, Shaw LK, Delong ER, Califf RM, Pryor DB. Absence of sex bias in the referral of patients for cardiac catheterisation. N Engl J Med 1994;330:1101-6.
13 Pfeffer MA, Braunwald E, Moye LA, Basta L, Brown Jr EJ, Cuddy TE, et al Effect of captopril on mortality and morbidity in patients with left ventricular dysfunction after myocardial infarction: results of the survival and ventricular enlargement trial. N Engl J Med myocardial infarction

14 Tobin JN, Wassertheil-Smoller S, Wexler JP, Steingart RM, Budner N, Lense L, et al. Sex bias in considering coronary bypass surgery. Ann Intern Med 1987;107:19-25.

15 Warner KE, Goldenhar LM, McLaughlin CG. Cigarette advertising and magazine coverage of the hazards of smoking. N Engl J Med 1992;326:305-309.

16 Stampfer MJ, Colditz GA, Willett WC, Manson JE, Rosner B, Speizer FE, et al. Post menopausal oestrogen therapy and cardiovascular disease: ten year follow-up from the nurses' health study. N Engl J Med 1991;325:756-62.

17 Posthuma WFM, Westendorp RGJ, Vandenbroucke JP. Cardioprotective effect of hormone replacement therapy in postmenopausal women: is the evidence biased? BMJ 1994;308:1268-9.

18 Murabito JM, Evans JC, Larson MG, Levy D. Prognosis after the onset of coronary heart disease. An investigation of differences in outcome between the sexes according to initial coronary disease presentation. Circulation 1993;88:2548-55.

\title{
Sick doctors
}

\section{$A$ responsibility to act}

What if a consultant pathologist, working largely single handedly and responsible for reading all the specialised histological slides in a large group of hospitals, had manic depression and was prone to periodic bouts of mania that made him skim through large numbers of slides with only cursory scrutiny of them? Who would recognise that there was a problem? What action would be taken? Where would he be treated? When would the decision be taken that it was safe to allow him to return to work? Should there be continuing supervision, and how should it be organised?

This hypothetical example shows only some of the complex questions posed when doctors become ill or are known to be at risk of illness. Many perspectives can be adopted when the phenomenon of the sick doctor is considered: the need to protect patients, the duty of other doctors to report problems, the responsibility of a good employer to care for its staff, the legitimacy given to some types of chronic illness (for example, rheumatoid arthritis) and not to others (for example, drug and alcohol misuse), and whether doctors should be regarded as special cases or just like other employees.

It has long been recognised that doctors, as an occupational group, experience excess mortality from some causes, particularly suicide and self injury, poisoning, and cirrhosis of the liver. ${ }^{1}$ Reviews of morbidity among doctors have suggested a relatively high occurrence of psychiatric and stress related disorders as well as drug and alcohol misuse. ${ }^{23}$

A study carried out under the auspices of the Nuffield Provincial Hospitals Trust set out to explore perceptions of and attitudes to sick doctors as well as the provision of services for them in eight health service localities (p 561).45 The messages from the interviewees (senior and junior doctors, health service managers, industrial relations officers, and representatives of community health councils) were that doctors' health problems are poorly dealt with, interventions come too late, and appreciable attitudinal and organisational barriers exist to the uptake of services. Respondents' views on why help is not sought encompassed the stigmatising nature of illness for doctors (and consequent denial), misguided professional loyalty, attitudes formed during medical training, the perceived irrelevance of services (particularly occupational health services), and a tradition of self treatment and direct self referral to hospital consultants.

The main ways of helping sick doctors currently lie within a series of national procedural frameworks and with local health services: the health committee of the General Medical Council, the National Counselling Service for Sick Doctors, the hospital based mechanism for preventing harm to patients (known as the "three wise men" procedure), ${ }^{6}$ and, for general practitioners, a similar mechanism based on local medical committees. In addition, at local level, occupational health services and general health services have a role. In some places special initiatives have been developed. For example, a "house call" scheme run by a department of psychotherapy in association with the postgraduate dean provides confidential counselling and support for junior hospital doctors who are stressed or distressed. ${ }^{7}$

\section{Doctors should seek help early}

The Nuffield study draws attention to the weaknesses of present procedures and services. It calls for widespread change, with an emphasis on encouraging doctors to behave more like other patients and to seek help early through conventional referral mechanisms. A much greater role is envisaged for general practice and stronger occupational health services.

Although we must accept the criticism that existing procedures are patchy and not well known or understood, we should remember that they are regularly used. Indeed, these formal mechanisms have been the only systematic and serious attempt to deal with the problem of sick doctors. Involvement of the General Medical Council has the drawback that it is defined in statute and is strictly speaking limited to doctors who are severely impaired. Moreover, some doctors are intimidated by the council's disciplinary connotations. The General Medical Council has, however, considerably widened its remit and taken important steps forward in dealing with sick doctors, particularly under the recently retired chairman of its health committee. ${ }^{8}$ Consequently, the council's health committee has played an invaluable part, particularly in respect of rehabilitating sick doctors, ${ }^{9}$ one of the most difficult aspects to deal with. Similarly, the National Counselling Service for Sick Doctors offers an informal route for referral and is dealing with a rising number of cases (currently some $300-400$ a year). ${ }^{10}$

The three wise men procedure, in which a panel of consultants in a hospital has the power to intervene when patients are at risk of harm because of a doctor's illness, is often criticised as ineffective and not widely known. This is 
partially justified. The panel invariably operates in secret. Indeed, I remember a complaint from a consultant who came to me in despair about a sick colleague; he had asked the hospital administrator for the name of the chairman of the three wise men and had been told that this information was confidential. Experience suggests, however, that the mechanism can work well: many examples exist of sick doctors who have been identified by it, treated, and successfully returned to work without anyone in the hospital being aware of the problem. The same is true of the work of members of local medical committees on behalf of sick general practitioners. Occupational health services face the difficulty that many doctors are reluctant to use them because they fear that such services have too close a relationship with management and that they will be seen as a problem that is better disposed of than rehabilitated.

Any consideration of the problem of sick doctors must recognise that they are not a homogenous group. Some illnesses affect a doctor's competence and clinical performance in the short term, periodically, or permanently. In such cases the main concern is to balance considerations of patients' safety and quality of care with those relating to the health and welfare of the doctor. Decisions regarding this group of sick doctors can be extraordinarily difficult to take at local level. Strongly held and polarised views often exist among doctors, managers, and nursing staff: some may believe that consumer protection should be paramount while others want to ensure that colleagues are supported, helped, and enabled to continue to fulfil the roles for which they were trained.

\section{Drug misusers present special problems}

A group with different needs is those doctors whose ill health affects their behaviour rather than their competence itself. Prominent among this group are drug and alcohol misusers, and difficult judgments have to be made about how much their behaviour affects patients' care, professional relationships, and teamwork. Here the opportunities for stigma and hostile attitudes are particularly great, and so decisions about how and when to treat, as well as whether the doctor should remain at work, are particularly important.

Junior doctors may have special problems with the stress and emotional effects of jobs with heavy workloads, and high pressure, which demand decisions that they feel ill equipped to take. This is exemplified by one of the doctors helped by "house call"?: "Lonely and angry in the middle of the night. Supposed to be in control. Faced with someone in pain and you don't know how to sort it out." The strategies here should involve not just measures to reduce the volume and intensity of work currently under way ${ }^{11}$ but a more structured approach to supervision, support, and education. The problem of helping doctors to avoid stress or cope with it is not restricted to junior doctors and has not yet been seriously addressed in a health care system that is still undergoing substantial organisational and technological change. The management of change is an art that the NHS has yet to perfect.

\section{Something central needed}

Sick doctors can have very different needs, they can generate complex problems, and how these problems are handled can pose enormous challenges. Completely devolving responsibility to local services is therefore not the answer. The creation of a new and cohesive national framework, drawing on the experience of existing mechanisms but using local systems and networks to identify problems, make assessments, and recommend treatment, should be considered by the working party that is being established by the Nuffield Provincial Hospitals Trust under the chairmanship of Sir Maurice Shock.

Those who do not wish doctors to be viewed any differently from other health service staff must recognise that they are expensive to train and to pay, while their clinical decisions account for a large part of the service's expenditure. Moreover, their health is vital to the safety and quality of patients' care. This is a special problem that has been around for a long time. The medical profession and the health service have a responsibility to produce a definitive, effective solution to the problem of sick doctors.

Northern and Yorkshire Regional Health Authority,

LIAM J DONALDSON Regional general manager Newcastle upon Tyne NE6 4PY

\footnotetext{
1 Office of Population Censuses and Surveys. Occupational mortality 1979-80, 1982-83. London HMSO, 1986.

2 Pilowski L, O'Sullivan G. Mental illness in doctors. BMJ 1989;298:269-70.

3 BMA Board of Science and Education. The morbidity and mortality of the medical profession. London: BMA, 1993.

4 Nuffield Provincial Hospitals Trust. The provision of medical services to sick doctors: a conspiracy of friendliness? London: NPHT, 1994.

5 Court C. Study highlights stigma of sick doctors. BMF 1994;309:561-2.

6 Department of Health and Social Security. Prevention of harm to patients resulting from physical or mental disability of hospital or community medical or dental staff. London: DHSS, 1986. or mental disabih

7 Mushet G. Breaking the silence. New deal news. London: NHS Management Executive, 1993.

8 Allibone A. Who treats the doctor? Practitioner 1990;234:984-7.

9 NHS Management Executive. Work re-entry scheme for sick doctors identified by the health committee of the General Medical Council. London: NHSME, 1993. (HSG(93)25.)

10 Brandon S. Three wise men procedure is effective. BMF 1994;308:1641.

11 NHS Management Executive. Funior doctors : the new deal. London: NHSME, 1991. (EL(91)82.)
} 